\title{
TOWARDS MONITORING GROUNDWATER TABLE DEPTH IN PEATLANDS FROM SENTINEL-1 RADAR DATA
}

\author{
Tina Asmu $\beta^{l}$, Michel Bechtold ${ }^{2}$, Bärbel Tiemeyer ${ }^{1}$ \\ ${ }^{1}$ Thünen Institute of Climate-Smart Agriculture, Braunschweig, Germany \\ ${ }^{2}$ KU Leuven, Department of Earth and Environmental Sciences \\ and Department of Computer Science, Belgium
}

\begin{abstract}
Groundwater table depths (WTD) control peat formation and greenhouse gas emissions from peatlands. Therefore, monitoring WTD is of great interest for restoration and climate change mitigation actions. In shallow groundwater systems such as peatlands, moisture in the topsoil is influenced by and often in hydrostatic equilibrium with WTD. Sentinel-1 provides C-band radar data with high temporal and spatial resolution. Since backscattered microwave radiation is sensitive to the soils' dielectric permittivity of the first centimeters, radar data provides a promising tool to obtain spatial information not only on soil moisture but also on WTD. We evaluate the correlation between time series of backscatter coefficients $\sigma^{0}$ and WTD measured in situ at $>50$ dip wells using a change detection approach. Study area is the Drömling peatland in Germany. Overall, we observe an increase in $\sigma^{0}$ with shallower WTD. For a few sites and time periods $\sigma^{0}$ also decreased during wettest conditions and related partial inundation. Preliminary results from the Drömling peatland show that temporal correlation coefficients vary strongly among sites and reach on average 0.57 . Time series indicate that the $\sigma^{0}$ WTD dependency partly disappears during summer.
\end{abstract}

Index Terms - peatland, Sentinel-1, radar, hydrology, soil moisture

\section{INTRODUCTION}

In peatlands, groundwater table depth (WTD) is an important factor controlling vegetation composition, water quality and greenhouse gas (GHG) emissions. Shallow WTD are essential requirements for peat formation from species such as Sphagnum spp. or Carex spp. under anaerobic conditions. Deep WTD causes degradation of the peat layer due to consolidation and oxidation of the organic material. In Germany, most peatlands are drained for agriculture or forestry, mainly for use as grasslands. Drained peatlands and other organic soils have shown high carbon dioxide $\left(\mathrm{CO}_{2}\right)$ and nitrous oxide $\left(\mathrm{N}_{2} \mathrm{O}\right)$ emissions [1]. During inundation, high methane $\left(\mathrm{CH}_{4}\right)$ emissions may occur [2]. As in other countries with a high share of agriculture and forestry on organic soils, drained organic soils contribute $4.9 \%$ to national GHG emissions in Germany, which is the largest part of the sectors agriculture and land use, land use change and forestry (LULUCF) [3].

So far, WTD monitoring in peatlands is mostly solely based on point information derived from a limited number of dip wells. The potential of moisture-sensitive radar remote sensing to add spatial information to the point information on WTD is largely unexploited. WTD maps of complete spatial coverage are required for monitoring the success of restoration and climate change mitigation measures and have the potential to strongly improve emission reporting.

Sentinel-1 is a satellite mission of the European Space Agency for radar observations. The two satellites of the Sentinel-1 mission were launched in 2014 (Sentinel-1A) and 2016 (Sentinel-1B). The Sentinel-1 satellites use synthetic aperture radar (SAR) operating in C-band. The system transmits electromagnetic radiation with a frequency of $5.4 \mathrm{GHz}$ to the earth's surface und detects the backscatter, which is the amount of radiation reflected back to the sensor. Several operation modes of the system are available with different spatial resolutions. Standard mode for land surfaces is the Interferometric Wide Swath (IWS) mode with spatial resolution of about $10 \mathrm{~m}$. The mission is designed for a long-term observation and therefore offers possibilities for a monitoring with high spatial and temporal resolution.

With this study we investigate the potential use of Sentinel-1 radar data for monitoring near-surface water table depth dynamics in different peatlands in Germany, for which high quality in situ data on WTD is available.

\section{BACKSCATTER FROM PEATLANDS}

In the first place, recorded C-band backscatter coefficients $\sigma^{0}$ are sensitive to vegetation characteristics. Over land surfaces with low aboveground biomass (here: grasslands), $\mathrm{C}$-band radiation partly penetrates through the vegetation and one or two $\mathrm{cm}$ into the soil and $\sigma^{0}$ is thus further sensitive to surface roughness and the dielectric permittivity of the penetrated top soil layer. The dielectric permittivity of water $(\sim 80)$ is much higher than of soil $(\sim 4)$. Therefore, 
dielectric permittivity in soil is mostly influenced by water content. Soil moisture of topsoils has been derived successfully from C-band radar [4].

During inundation specular reflection on the smooth water surface leads to low backscatter. Because inundation frequently increases methane emissions from peatlands, a threshold of low backscatter can be used for estimating methane fluxes [5] as long as there are no periods of very low soil moisture. However, there are only a few attempts to use backscatter for monitoring WTD also in peatlands with periods of deeper WTD [6,7].

\section{DATA AND METHODS}

Deriving information about WTD from C-band radar is based on the dependency between WTD and topsoil water content.

At shallow WTD, topsoil water content is influenced by WTD. The influence is site-specific and controlled by the soil hydraulic properties and the hydraulic gradients within the soil. When assuming that during shallow WTD, topsoil water content is in hydrostatic equilibrium with WTD, there is a direct relationship between topsoil water content and WTD, and thus also between WTD and soil moisture sensitive contributions to $\sigma^{0}$. In our study, we analyse the temporal correlation between $\sigma^{0}$ and WTD measured in situ in monitoring wells.

\subsection{Study site and in situ data}

The study is carried out at the Drömling peatland area in Germany. The Drömling is a nature park with a mixed land use with cropland, grassland under intensive and extensive use, rewetted areas and mainly shallow fen peat [8]. Here, we focussed on grassland being the major land use of organic soils both at the Drömling and in Germany. Main vegetation types of the grasslands in the study area are mesophilic and wet grassland. The WTD and land use intensity, i.e. the number of cuts and grazing days are spatially strongly variable. Daily WTD data were available from about 50 WTD observation wells and served as in situ reference data. The WTD averaged over all sites was about $0.5 \mathrm{~m}$ during the study period (01/2015 to 09/2016). Inundation occasionally occurred only at few sites during winter.

Soils in the study area comprise mainly shallow and strongly humified fen peats (Eutric Histosols), but there are also sandy soils rich in organic matter (Humic Gleysols) and sand-covered Histosols.

To analyse the dependency of topsoil moisture on WTD and to determine potential site-specific WTD thresholds at which the capillary link gets lost, we additionally measured campaign-wise topsoil moistures and determined site-specific water retention characteristics at selected locations.

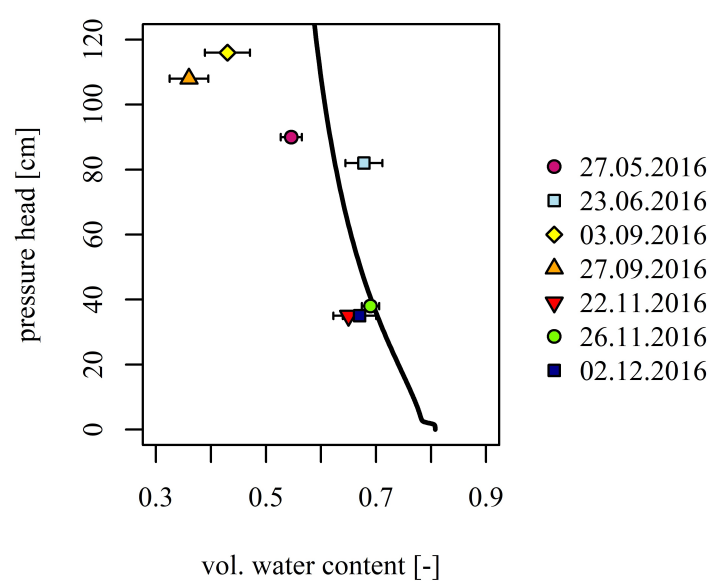

Fig. 1. Topsoil moisture from sampling campaigns and $95 \%$ confidence intervals from one fen site at different water table depths compared to laboratory-based water retention curve to estimate strength of capillary connection between WTD and topsoil moisture.

\subsection{Backscatter coefficients}

The Sentinel-1 radar data are acquired since January 2015 as Level-1 ground-range detected (GRD) product from the Interferometric wide swath (IWS) operation mode. Data is available in dual polarization with VV (vertical transmission and vertical reception) and $\mathrm{VH}$ (vertical transmission and horizontal reception).

Considering both satellites and varying viewing geometries the temporal resolution of the data is up to 2 to 3 days. However, available scenes are filtered for soil freezing and prior recent precipitation because both are expected to strongly affect the correlation between WTD and $\sigma^{0}$.

The radar data is pre-processed with the Sentinel-1 Toolbox [9] from which $\sigma^{0}$ is derived. A spatial median speckle filter was used to reduce speckle noise. The different incidence angles, $\theta$ (here: $\sim 35^{\circ}$ and $\sim 44^{\circ}$ ), were normalized to a reference incidence angle $\theta_{r}$ applying the crossover angle concept [10] in a simplified linear form [7]. Slope climatologies of the $\theta$-dependency of $\sigma^{0}$ were derived from Sentinel images for each observation well. For each day of year, a slope was fitted to the data of the two years within time windows of approx. six months. In general, slope showed higher (less negative $\rightarrow$ shallower) values in summer when vegetation is higher. The method has already been applied to ENVISAT ASAR data where it is described in detail [7].

\section{RESULTS AND DISCUSSION}

The topsoil moisture data from several campaigns showed a hydrostatic equilibrium until about 60 and $80 \mathrm{~cm}$ (Fig. 1) at two tested fen sites. The strong capillary connection is 

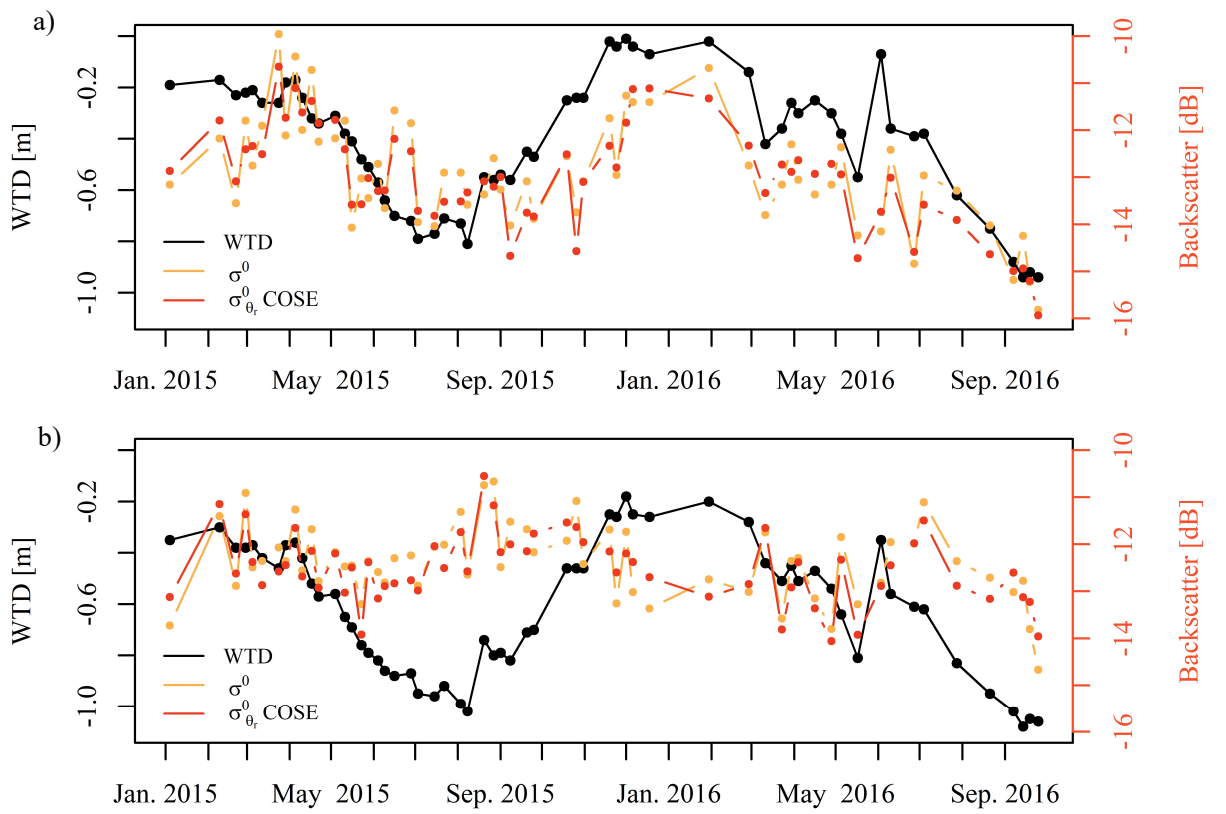

Fig. 2. Exemplary time series of backscatter coefficient $\sigma^{0}$ for ascending scenes and water table depth, WTD, at two different monitoring sites with a correlation coefficient of 0.7 (a) and 0.2 (b) with and without application of the $\underline{\text { Cross}} \underline{\mathrm{O} v e r}$ angle concept using slopes derived from SEntinel-1 data (COSE). The dip wells are located at sand-covered fen peat.

promising for the application of radar data but more research needs to be done to determine the overall limits of the application.

Preliminary results of the backscatter analysis show a mean temporal correlation coefficient of 0.54 without and 0.57 with application of the crossover angle concept when averaging over all observation wells. At several sites, $\sigma^{0}$ follows the short-term as well as seasonal dynamics of WTD fairly well (Fig. 2a). Increased $\sigma^{0}$ mostly coincided with shallower WTD. At several sites, it could be observed that during summer changes of $\sigma^{0}$ were less related to WTD changes. This could be related to the higher aboveground biomass in summer and/or the loss of the capillary connection at the typically deeper summer WTD. Further, parcels are rather small in the study area and small neighbouring shrubs and ditches could also have influenced backscatter dynamics blurring the $\sigma^{0}$-WTD dependency.

At few sites the correlation coefficients were very low (Fig. 2b) and further analysis is required to identify related limiting factors. Soil type did not determine the strength of the $\sigma^{0}$-WTD relationship.

At most sites normalization and crossover angle concept slightly increased correlation coefficients but with overall minor changes to original data. Our study expands the results shown in [7] and demonstrates the advantages of higher spatial and temporal resolution data provided by Sentinel-1 to monitor WTD dynamics in the land cover mosaic of managed peatlands.

\section{PROSPECTS}

On such an early development stage this method offers promising results for further progress. At several dip wells with shallow WTD good correlation coefficients were observed between $\sigma^{0}$ and WTD. However, highly diverse vegetation in peatlands makes interpretation more difficult. Our study will be expanded to further study areas:

- Schwäbisches Donaumoos: mixed land use with cropland, grassland under intensive and extensive use, rewetted areas, deep fen peat.

- Gnarrenburger Moor: intensive grassland use on deep bog peat, mainly deep groundwater levels, experimental fields with controlled drainage.

- Wesermarsch: intensive grassland use both as meadow and pasture, fen peat covered with riverine silt.

Spatial information on WTD would benefit many applications. In peatlands under agricultural use water management could be optimized by improved WTD and moisture estimates from hydrological models that include added value from satellite observations. Furthermore, the method provides new options for spatially quantifying GHG emissions, especially $\mathrm{CO}_{2}$, and evaluating climate mitigation measures. 


\section{ACKNOWLEDGEMENTS}

We would like to thank Ullrich Mäck (ARGE Schwäbisches Donaumoos), Fred Braumann (Naturpark Drömling) and Heinrich Höper, Arne Tegge and Stefan Frank (State Authority for Mining, Energy and Geology Lower Saxony) for granting us access to their groundwater level data.

\section{REFERENCES}

[1] B. Tiemeyer, E.A. Borraz, J. Augustin, M. Bechtold, S. Beetz, C. Beyer, M. Drösler, M. Ebli, T. Eickenscheidt, S. Fiedler, C. Förster, A. Freibauer, M. Giebels, S. Glatzel, J. Heinichen, M. Hoffmann, H. Höper, G. Jurasinski, K. Leiber-Sauheitl, M. PeichlBrak, N. Roßkopf, M. Sommer and J. Zeitz, "High emissions of greenhouse gases from grasslands on peat and other organic soils", Global Change Biology, vol. 22, pp. 4134-4149, 2016.

[2] P.E. Levy, A. Burden, M.D.A. Cooper, K.J. Dinsmore, J. Drewer, C. Evans, D. Fowler, J. Gaiawyn, A. Gray, S.K. Jones, T. Jones, N. P. McNamara, R.Mills, N. Ostle, L.J. Sheppard, U. Skiba, A. Sowerby, S.E. Ward and P. Zielinski, "Methane emissions from soils: synthesis and analysis of a large UK data set”, Global Change Biology, vol. 18, pp. 1657-1669, 2012.

[3] UBA (Umweltbundesamt), "Submission under the United Nations Framework Convention on Climate Change and the Kyoto Protocol 2014", National Inventory Report for the German Greenhouse Gas Inventory 1990-2012, Climate Change 28, Dessau-Roßlau, Germany, 2014.
[4] W. Wagner, G. Lemoine and H. Rott, "A Method for Estimating Soil Moisture from ERS Scatterometer and Soil Data," Remote Sensing of Environment, vol. 70, pp. 191-207, 1999.

[5] J. Reschke, A. Bartsch, S. Schlaffer and D. Schepaschenko, "Capability of C-Band SAR for Operational Wetland Monitoring at High Latitudes," Remote Sensing, vol. 4, pp. 2923-2943, 2012.

[6] J.-W. Kim, Z. Lu, L. Gutenberg, Z. Zhu, "Characterizing hydrologic changes of the Great Dismal Swamp using SAR/InSAR", Remote Sensing of Environment, vol. 198, pp. 187202, 2017.

[7] M. Bechtold, S. Schlaffer, B. Tiemeyer and G. De Lannoy, "Inferring water table depth dynamics from ENVISAT-ASAR Cband backscatter over a range of peatlands from deeply-drained to natural conditions", Remote Sensing, vol. 10, pp. 536-557, 2018.

[8] J. Untenecker, B. Tiemeyer, A. Freibauer, A, Laggner, F, Braumann, and J. Luterbacher, "Fine-grained detection of land use and water table changes on organic soils over the period 19922012 using multiple data sources in the Drömling nature park, Germany", Land Use Policy, vol. 57, pp. 164-178, 2017.

[9] European Space Agency, Sentinel-1 Toolbox (Version 6.0), retrieved February 2018 from http://step.esa.int/main/download/.

[10] W. Wagner, G. Lemoine, M. Borgeaud and H. Rott, "A study of vegetation cover effects on ERS scatterometer data", IEEE Transactions on Geoscience and Remote Sensing, vol. 37, pp. 938948, 1999. 